\title{
O LIVRO DIDÁTICO NA EDUCAÇÃO FÍSICA ESCOLAR: VISÃO DE PROFESSORES E ALUNOS
}

\author{
André Luís Ruggiero Barroso \\ Universidade Estadual Paulista, Rio Claro, São Paulo, Brasil \\ Suraya Cristina Darido \\ Universidade Estadual Paulista, Rio Claro, São Paulo, Brasil
}

\begin{abstract}
Resumo
O objetivo do estudo foi identificar junto a professores de Educação Física (EF) escolar as possibilidades e as dificuldades de utilização do livro didático na prática pedagógica e verificar o envolvimento dos alunos durante as atividades norteadas por esse tipo de material. Utilizou-se o método da pesquisa-ação, tendo a participação de professores dos anos finais do Ensino Fundamental. Os professores mostraram-se favoráveis à utilização do livro didático, desde que tenham liberdade para a realização de alterações no material. Quanto aos alunos, houve melhor aceitação em tarefas curtas. Assim, entende-se que a utilização do livro didático na EF escolar pode oferecer benefícios no desenvolvimento das aulas.
\end{abstract}

Palavras-chave: Escola. Educação Física. Material didático.

\section{Introdução}

O material didático pode se caracterizar de diferentes formas, como material audiovisual, material vinculado à informática (internet, hipermídia, multimídia, ferramentas para educação a distância etc.), material impresso produzido por meio de apostilas, livros didáticos, livros paradidáticos, entre outros.

Quanto ao livro didático, material que é tradicionalmente, ao longo das últimas décadas, utilizado por vários componentes curriculares no âmbito escolar, este sofre inúmeras críticas. Entre elas, as relacionadas aos seus autores, aos critérios de sua distribuição nas redes de ensino e essencialmente na forma de sua utilização pelos professores.

De acordo com Apple (1995), o livro estabelece e direciona o que deve ser ensinado nas escolas e, como os professores invariavelmente não têm acesso à elaboração desse material, os governantes municipais, estaduais e/ou federais podem definir o conhecimento a ser ensinado e a forma como deve ser conduzido, os objetivos e os resultados do processo de ensino, tornando-o uma ferramenta de controle.

Segundo as investigações realizadas por Munakata (2003) sobre os livros escolares durante o regime militar em nosso país, as críticas foram incisivas quanto à adoção de livros didáticos, por exemplo, quando os críticos apontavam que eles davam sustentação ideológica ao governo.

Havia também a crítica por esse material servir de "muleta" para os professores atuarem na prática pedagógica, ou seja, conforme as análises de Munakata (2003), a utilização de 
livros didáticos era considerada pelos críticos como uma sustentação à ideologia oficial, colaborando com a ditadura; também impedia o processo educacional voltado para uma perspectiva criativa, reflexiva e crítica. Contudo, salienta-se que no Brasil, desde 1985, há o Programa Nacional do Livro Didático ${ }^{1}$, dando autonomia aos docentes para a escolha do material.

Sacristán (2000), ao tecer críticas ao livro didático, adverte que o uso deles pode caracterizar um controle sobre a prática dos professores, pois o livro, em boa parte das vezes, direciona o currículo, bem como os conteúdos, as estratégias de ensino e as atividades a serem ministradas aos alunos. Conforme esse autor, a obediência fiel a esse tipo de material leva à desprofissionalização dos professores atuantes no ambiente escolar.

Respeitam-se os apontamentos realizados referentes às críticas ao livro didático, mas se torna necessário refletir em contraposição, pois se tem a ideia de que esse tipo de material pode ser utilizado como um dos instrumentos da prática pedagógica, mas não o único; também o professor não deverá se tornar um "escravo" desse material, mas sim utilizá-lo conforme as necessidades do conteúdo a ser desenvolvido.

Concorda-se com Bittencourt (2010) quando a autora afirma que "o livro é um objeto feito para o professor e é dependente do uso que o professor faz dele" (p. 545). Também nesse sentido, Zabala (1998) adverte que o fundamental não está na discussão entre a utilização ou não do material didático, mas sim no entendimento referente a quais materiais utilizar e como deverão ser utilizados.

Nessa perspectiva, Polidoro e Stigar (2010) alegam que o livro didático apresenta-se como instrumento determinante para a aprendizagem, servindo como um suporte desse processo e um referencial para a execução de tarefas além da sala de aula. Também se destaca o posicionamento de Darido et al. (2010), ao sinalizarem que esse tipo de material tem o propósito de servir como um referencial pedagógico e deve ser transformado pelo professor, de acordo com suas necessidades e realidades educacionais.

No caso da Educação Física, identifica-se certo "atraso" em relação aos demais componentes curriculares no que se refere à utilização de livros didáticos. Isso pode ser explicado pelo percurso histórico dessa área de conhecimento, pois a Educação Física escolar, até o início dos anos 1980, foi direcionada apenas para a aprendizagem de movimentos corporais, ligada ao propósito de aprender a fazer, caracterizando a dimensão procedimental do conteúdo (DARIDO e RANGEL, 2005).

Esse fato é confirmado no estudo de Faganello (2008), quando verificada a pequena quantidade de livros que superam atividades direcionadas ao ensino de gestos técnicos específicos do atletismo. A autora, durante o levantamento dos livros pertencentes à categoria aspectos didáticos, faz uma subdivisão entre técnicos e pedagógicos para o ensino da modalidade esportiva, chegando aos seguintes números: 16 livros técnicos e 7 livros pedagógicos ${ }^{2}$.

Os livros técnicos têm o propósito de ensino dos gestos técnicos da modalidade esportiva seguindo os padrões do treinamento esportivo, sendo direcionados para futuros atletas, enquanto os livros pedagógicos têm o intuito de oferecer um melhor conhecimento do atletismo, voltado para a formação dos alunos, ocorrendo a aprendizagem dos movimentos específicos, porém sem a necessidade de execução eficiente deles (FAGANELLO, 2008).

De acordo com Faganello (2008), os livros classificados em seu estudo como técnicos serviam como norteadores da docência do professor. Cita, inclusive, que até a década de 1980 a Educação Física escolar tinha como objetivo a busca de talentos esportivos, sendo as aulas

\footnotetext{
${ }^{1}$ O Programa Nacional do Livro Didático está inserido no Fundo Nacional de Desenvolvimento da Educação. Disponível em:

〈http://www.fnde.gov.br/programas/livro-didatico/livro-didatico-funcionamento $>$ Acesso em: 2 jun. 2017.

2 Para o levantamento das obras, foi utilizado o acervo disponível nas bibliotecas das universidades públicas de São Paulo (USP, UNESP, UNICAMP e UFSCar), coletando os livros nacionais, portugueses e traduzidos para o português, específicos do atletismo.
} 
caracterizadas pelo ensino de movimentos específicos referenciados com base nos padrões técnicos estabelecidos em diferentes modalidades esportivas. Ou seja, os materiais produzidos eram direcionados exclusivamente ao "aprender a fazer".

Essa questão é reforçada por Souza Júnior e Galvão (2005), ao afirmarem que apenas recentemente a área iniciou a constituição de saberes propriamente científicos, indo além das questões vinculadas à denominada dimensão procedimental do conteúdo, preocupando-se também em abordar saberes conceituais e atitudinais.

Tem-se verificado em encontros científicos e em publicações de artigos da área da Educação Física uma discussão mais frequente sobre a possibilidade de trabalhar com o livro didático durante as aulas no ambiente escolar. Essa realidade pode ser constatada em estudos de Galatti (2006), Rodrigues (2009), Impolcetto (2012), Rufino (2012) e também materializada nas propostas curriculares de alguns estados (PARANÁ, 2008; SÃO PAULO, 2008; RIO GRANDE DO SUL, 2009), cujos documentos apresentam material didático tanto para o professor como para o aluno.

Defende-se a ideia de que é possível oferecer ao professor de Educação Física, atuante em diferentes níveis de ensino, um material de apoio que sirva como mais um instrumento para qualificar a sua prática pedagógica. Esse material não teria o intuito de causar uma dependência direta do profissional, mas oferecer subsídios que contribuam no processo de ensino e aprendizagem.

Assim, o objetivo deste estudo foi identificar junto aos professores de Educação Física escolar as possibilidades e as dificuldades de utilização do livro didático na prática pedagógica, como também verificar o envolvimento dos alunos durante as atividades norteadas por esse tipo de material.

\section{Procedimentos metodológicos}

Para o desenvolvimento desta pesquisa, foi realizada uma abordagem de cunho qualitativo, sendo utilizado o método da pesquisa-ação (THIOLLENT, 2003).

Conforme Thiollent (2003), na pesquisa-ação ocorre uma inter-relação do objetivo prático e do objetivo de conhecimento, pois se, por um lado, o maior conhecimento proporcionará um melhor desenvolvimento da ação, em contrapartida, as próprias exigências da prática irão requerer uma dedicação pela busca do conhecimento, ocasionando, dessa forma, o estabelecimento de equilíbrio entre os objetivos.

Para Bracht (2002), a pesquisa-ação proporciona um percurso efetivo no desenvolvimento do estudo, uma vez que estabelece um vínculo entre o conhecimento da realidade da prática educacional e a ação pedagógica.

Ressalta-se que nesse método os participantes atuam como sujeitos investigadores de sua própria prática, ocorrendo um envolvimento e uma ação efetiva de todas as pessoas que integram a pesquisa (BRACHT, 2002; THIOLLENT, 2003; ELLIOTT, 2005).

Thiollent (2003), ao identificar diferenças entre a pesquisa convencional e a pesquisaação, aponta que na primeira os sujeitos participantes se restringem a transmitir as informações e, no momento da ação, tornam-se simples executores; na segunda, por seu turno, pressupõem-se a participação e a ação efetiva de todos os envolvidos no estudo - pesquisadores e participantes.

É importante advertir que originalmente o método da pesquisa-ação apresenta o levantamento dos problemas ocorridos na atuação profissional, identificados pelos profissionais que lidam diretamente com a prática pedagógica, como no estudo desenvolvido por Bracht (2002) com professores de Educação Física em um curso de especialização promovido pela Universidade Federal do Espírito Santo. Entretanto, na própria área da Educação Física escolar, pesquisas têm demonstrado resultados satisfatórios, quando o problema inicial não é le- 
vantado pelos participantes do trabalho, mas sim apresentado pelo próprio pesquisador. Esse procedimento ocorreu nos estudos de Betti (2003), Bustamante (2003), Impolcetto (2005; 2012), Barroso (2008) e Rufino (2012).

Para a realização do estudo, foi utilizado o material didático - caderno do professor (LIÇÕES DO RIO GRANDE, 2009b) e caderno do aluno (LIÇÕES DO RIO GRANDE, 2009a) - pertencente ao Referencial Curricular do Estado do Rio Grande do Sul (RIO GRANDE DO SUL, 2009), apresentando uma unidade didática que tem como objetivo principal o ensino de um sistema de classificação do esporte (GONZÁLEZ, 2004; 2006), destinado a estudantes do $8^{\circ}$ e do $9^{\circ}$ anos do Ensino Fundamental.

A opção pela escolha do material didático pertencente ao estado do Rio Grande do Sul se deu por tratar de aspectos universais presentes no mundo do esporte, portanto não apresentando problemas quanto a sua utilização entre professores que atuam em outro estado do país, como foi o caso desta pesquisa. Aliado a isso, é reforçado que esse modelo de classificação presente no material didático utilizado no estudo foi adotado para estruturação do conteúdo esporte no documento da Base Nacional Comum Curricular referente ao período do Ensino Fundamental - anos iniciais e finais (BRASIL, 2017).

Participaram inicialmente da pesquisa oito professores de Educação Física - quatro homens e quatro mulheres. Entretanto a professora 3, devido a questões internas da unidade escolar, não desenvolveu as aulas, participando apenas do início da pesquisa. Sendo assim, contou-se efetivamente com sete professores para o desenvolvimento completo do estudo, atuantes em duas escolas privadas e em cinco escolas públicas municipais, localizadas nas cidades de Campinas, Jaguariúna, Mogi Guaçu e Paulínia, todas no interior do estado de São Paulo.

No período da pesquisa, os professores tinham de 26 a 42 anos, com menor e maior tempo de formação de 4 e 9 anos. O tempo de atuação na escola variou entre 3 e 7 anos, e o de atuação específica no $8^{\circ}$ e $9^{\circ}$ anos apresentou mínimo de 2 e máximo de 6 anos.

Para o desenvolvimento do trabalho, as atividades concentraram-se essencialmente em três etapas: apresentação aos professores do material didático utilizado na pesquisa, desenvolvimento das aulas dos professores com seus respectivos alunos e avaliação do material didático e da participação dos alunos nas tarefas.

Foram realizados dez encontros de trabalho, com duração entre uma hora e meia e duas horas e meia cada um, marcados por discussões entre o pesquisador e os participantes a partir da utilização de perguntas semiestruturadas. Os encontros ocorreram no intervalo entre duas semanas e dois meses. O período mais longo de intervalo justificou-se pela necessidade de os professores terem tempo suficiente para desenvolverem as aulas com seus respectivos alunos. Ressalta-se que, durante o desenvolvimento dessas aulas, os professores utilizaram um diário de campo para registrar as informações e apresentá-las posteriormente nos encontros com o pesquisador.

A forma de registro dos encontros ocorreu por meio de aparelho de gravação, sendo as falas posteriormente transcritas na íntegra em documento do Microsoft Office Word, possibilitando, assim, uma análise dos dados obtidos nas discussões entre o pesquisador e os participantes da pesquisa.

Os professores desenvolveram as aulas em suas respectivas unidades escolares, com os seguintes grupos: professora $1=$ três turmas de $9^{\circ}$ ano (escola pública); professor $2=$ três turmas de $8^{\circ}$ ano (escola pública); professora $4=$ uma turma de $8^{\circ}$ ano e uma turma de $9^{\circ}$ ano (escola particular); professor $5=$ uma turma de $8^{\circ}$ ano (escola pública); professora $6=$ duas turmas de $8^{\circ}$ ano (escola pública); professor $7=$ uma turma de $8^{\circ}$ ano (escola particular); professor $8=$ uma turma de $9^{\circ}$ ano (escola pública).

Os dados obtidos nos encontros envolvendo o pesquisador e os participantes da pesquisa passaram por uma análise crítica dos conteúdos (BARDIN, 1991), para então se chegar 
à discussão dos resultados, estruturada em dois momentos, ambos estabelecidos a partir dos relatos e debates realizados com os professores: possibilidades e dificuldades de utilização do material didático nas aulas de Educação Física escolar e envolvimento dos alunos na realização das tarefas do material didático.

Adverte-se que, para o desenvolvimento do estudo, os participantes assinaram o Termo de Consentimento Livre e Esclarecido e a pesquisa foi aprovada pelo Comitê de Ética em Pesquisa Envolvendo Seres Humanos, tendo registro CAAE: 27550314.3.0000.5465.

\section{Possibilidades e dificuldades da utilização do material didático nas aulas de Educação Física escolar}

Verificou-se inicialmente que nenhum dos participantes utiliza esse tipo de material em suas aulas. Entretanto, chamou a atenção o fato de os professores 2 e 7, mesmo tendo um material didático à disposição, não o empregarem em suas práticas pedagógicas. No caso do professor 2, na rede de ensino municipal em que atua, foi adquirido um material didático para o professor confeccionada por uma instituição privada, porém o grupo de professores do município avaliou que o material estava defasado em relação ao que já era desenvolvido nas escolas. Em relação ao professor 7, a rede de escolas privadas em que trabalha possui material didático para o professor, elaborada pela própria instituição, porém não é obrigatória a sua utilização e, conforme avaliação desse professor, o material específico da Educação Física apresenta-se ultrapassado e repetitivo nas séries escolares.

Nesse sentido, salienta-se que o professor que consegue avaliar a qualidade do material didático apresenta-se como um profissional crítico, não recebendo passivamente instrumentos de ensino a serem utilizados na prática pedagógica. Arroyo (2001) e Barros (2014) advertem que, quando chega ao professor um material didático de cuja elaboração ele não participou ou não teve a possibilidade de selecioná-lo, em muitas ocasiões, não apoia a sua utilização.

Também se constatou que nenhum dos professores conta com um material voltado para o aluno. Mesmo nas duas instituições escolares nas quais há um material apostilado destinado ao professor de Educação Física - professores 2 e 7 -, não existe um material direcionado ao aluno para o acompanhamento dos conteúdos durante as aulas. Munakata (2003) ressalta a necessidade de serem elaborados documentos específicos para professores e alunos quando se pensa em materiais que apresentem finalidades didáticas.

Rodrigues e Darido (2011) defendem a ideia de que o livro didático caracteriza-se como um material para o professor e para os alunos, pois, apesar de tratarem do mesmo conteúdo, a diferenciação se dá na necessidade de o material para o professor apresentar o conteúdo de forma aprofundada, contendo informações e conceitos com fundamentação alicerçada em detalhamentos teóricos; já o material para os alunos deve buscar uma dinamicidade no desenvolvimento do conteúdo e incentivá-los às resoluções de situações-problema e exercícios.

Quando indagados acerca das vantagens e desvantagens da utilização do livro didático como um instrumento pedagógico, os professores 1, 2 e 8 entenderam que, com o livro didático, os professores podem ter acesso a uma maior quantidade de informações, propiciando um melhor conhecimento do conteúdo contemplado, acrescentando contribuições àqueles que já apresentam certo domínio do tema, como também auxiliando os que apresentam pouco conhecimento. Servem, assim, como uma importante ferramenta educacional.

Os professores 1, 2 e 8 ainda acrescentaram que a possibilidade de ter à disposição esse tipo de instrumento pode contribuir na melhoria da qualidade das aulas, conforme relato do professor 8: "Na minha opinião acaba auxiliando o professor, mostrando possibilidades de utilização, com dicas e ideias de sistematização das aulas". 
As professoras 3 e 4 comentaram que o material didático oferece uma das possíveis formas de organização dos conteúdos, sendo determinante o professor realizar alterações de acordo com o seu planejamento e a realidade escolar. Entretanto, destacaram que o professor terá de introduzir o material de uma maneira que a parte teórica não seja exaustiva e que desperte interesse nos alunos pelo assunto.

Em estudo realizado por Rodrigues e Darido (2011) para o ensino da modalidade basquetebol, destacaram-se os seguintes pontos citados pelos participantes em relação às vantagens da utilização do livro didático: por oferecer uma sequência organizada do conteúdo, poderá direcionar o trabalho pedagógico do professor; pode se apresentar como uma fonte de atualização do professor; pode servir como um instrumento para colaborar nas reflexões acerca das ações do professor no seu dia a dia.

Os professores do estudo atual também mencionaram que é essencial o livro didático apresentar uma estrutura apropriada, ou seja, um instrumento que estabeleça relações com os conteúdos tratados pelos professores e que apresentem informações e atividades significativas para contribuir com o trabalho do professor e com o processo de aprendizagem dos alunos.

De acordo com Galatti, Paes e Darido (2010), o livro pode servir como um instrumento para mediar o processo de ensino, vivência e aprendizagem, possibilitando o direcionamento de uma sequência didática para o tratamento dos conhecimentos relativos aos conteúdos selecionados. Além disso, tem o potencial de oferecer aos alunos um material escrito com informações sobre o tema a ser estudado, incentivando a reflexão e certas conclusões, como também permite a estruturação dos textos em módulos para melhor organização das atividades pedagógicas (GALATTI; PAES; DARIDO, 2010).

Em relação às possíveis dificuldades na utilização do livro didático, o primeiro posicionamento foi da professora 1, mencionando a preocupação de deixar o professor dependente do material, bem como as atividades ocuparem um tempo excessivo das aulas, podendo assim prejudicar o desenvolvimento do componente curricular.

Eu tenho receio desse material engessar a gente, a gente ter que fazer aquilo e tem parte que não seria necessário pra aquele grupo que a gente dá aula. A gente poderia fazer uma coisa mais rica e não dar esse tempo, por conta de ter que cumprir o livro, eu tenho esse receio (PROFESSORA 1).

O relato apresentado pela professora 1 está vinculado à preocupação da desprofissionalização docente, pois poderá acarretar na diminuição/retirada de autonomia do professor, caso não seja possível que ele tenha liberdade para avaliar e utilizar o material de acordo com suas necessidades. Nesse sentido, Sacristán (2000) adverte para o perigo de o material didático se apresentar como um instrumento que não esteja articulado com o trabalho pedagógico do educador.

Essa questão também foi verificada no estudo de Ladeira et al. (2008), no qual os professores de Educação Física avaliaram como positiva a utilização do material didático para o professor e para os alunos nas escolas estaduais de São Paulo. Todavia, alertaram para a preocupação em relação ao material oferecido pelo governo do estado apresentar divergência quanto ao planejamento escolar elaborado pelo professor.

O professor 7 relatou uma particularidade ao citar sua realidade escolar, advertindo que os professores dos demais componentes curriculares que utilizam o material didático são obrigados a segui-lo fielmente, inclusive com o cumprimento de prazos, havendo a cobrança dos coordenadores da escola.

Entende-se que, dessa forma, cria-se outra situação problemática, pois os professores ficam reféns desse material, sem ter a liberdade e o tempo disponível para utilização de outros instrumentos. Inclusive reforça-se a importância de os professores intervirem no material que 
utilizam, realizando modificações nas estratégias, substituições de atividades, inclusões de tarefas, entre outras possibilidades, como defendem Sacristán (2000), Arroyo (2001), Bittencourt (2010) e Darido et al. (2010).

Pode-se acrescentar outro aspecto importante nesse rol de dificuldades, atentando para a questão de que não se deve interpretar que as aulas devam ser divididas em metade teórica e metade prática, pois o que se defende é justamente dar maior significado às práticas corporais tratadas na escola, procurando integrar aspectos conceituais e atitudinais às vivências de jogos, esportes, lutas, danças, ginásticas (BRASIL, 1997; BRASIL, 1998; BARROSO; DARIDO, 2010).

Ainda tratando da questão da necessidade de os professores interferirem no livro didático, destaca-se o posicionamento da professora 6: "[...] conhecendo a população da minha escola e conhecendo a população da escola do prof. 5, eu sei que se vier com um único material no município, eu vou ter que fazer algumas adaptações, diferente da dele, porque eu sei que o público é bem diferente".

Isso reforça o fato de que as alterações no material didático mostram-se determinantes na prática pedagógica do professor, pois, mesmo se tratando de alunos de escolas pertencentes a um único município, com a faixa etária semelhante e o ano escolar idêntico, têm que ser observadas as realidades de cada unidade escolar e de cada turma de alunos.

Outro aspecto foi salientado pelo professor 5, ao alertar que o material didático deva servir como um norte para o trabalho do professor e que este não deve ficar limitado a apenas um único instrumento para o tratamento dos conteúdos selecionados.

Na pesquisa de Rufino (2012), os participantes apontaram para a importância de haver uma diversidade de materiais didáticos referentes ao mesmo conteúdo, propiciando ao professor a utilização de diferentes fontes para estruturação de suas aulas. Esse aspecto também é defendido por Zabala (1998), quando ressalta a importância de os professores utilizarem mais de uma fonte de consulta, acrescentando a possibilidade de eles elaborarem o seu próprio material.

Outro aspecto significativo foi salientado pela professora 4, quando mencionou a importância de os alunos manusearem o material, favorecendo o processo de aprendizagem. Esse posicionamento foi reforçado pelo professor 2, conforme o exemplo:

Tinha aluno que queria levar o material pra casa. Os alunos perguntavam se podiam levar o material embora, pra mostrar pros pais, eles acharam interessante. A maioria dos alunos gostou, sempre tem aquele aluno que não quer fazer nada, mas pra maioria foi bom (PROFESSOR 2).

Nesse sentido, ressaltam-se os princípios de Munakata (2003), acompanhado por Darido et al. (2010), ao alertarem para a importância do livro direcionado para o aluno e do livro direcionado para o professor, quando se referem à utilização de materiais didáticos no ambiente escolar.

Reforça-se o fato de a ausência de livros didáticos não se apresentar como algo novo, pois este componente curricular tem a tradição de se concentrar em atividades de cunho prático, sem ocorrer uma apropriada contextualização por parte do professor e uma reflexão por parte dos alunos acerca das diversas práticas corporais existentes.

Entretanto, mesmo não sendo comum a utilização de livros didáticos no componente curricular Educação Física, salienta-se a estruturação da prática pedagógica de muitos professores procurando atribuir significado ao processo de ensino e aprendizagem das práticas corporais, fazendo uso de outros tipos de material, como colunas de jornais impressos, buscas na internet, reportagens de televisão, entre outros.

Ressalta-se que a importância pela busca da contextualização nas aulas de Educação Física escolar, visando a uma aprendizagem mais significativa dos estudantes acerca dos con- 
teúdos pertencentes a esse componente curricular, é cada vez mais defendida por autores da área, conforme pode ser observado em Caparroz (2005) e Betti e Zuliani (2009).

Nessa perspectiva, entende-se que a incorporação de livros didáticos na atuação do professor de Educação Física vai ao encontro da necessidade de tratar de questões que vão além da vivência e da experimentação de movimentos pertencentes ao universo da Cultura Corporal de Movimento. Assim, adverte-se para a importância na produção de materiais didáticos voltados para a área da Educação Física, com o propósito de servir como instrumentos pedagógicos para auxiliar o professor durante a prática pedagógica, mas que esse material seja utilizado de forma flexível, ou seja, tendo o professor a liberdade para realizar alterações nele, de acordo com sua necessidade e realidade educacional.

\section{Envolvimento dos alunos na realização das tarefas do material didático}

Tratando inicialmente da receptividade do material didático, os alunos dos professores 2, 5, 6, 7 e 8 apresentaram uma aceitação positiva, envolvendo nesse contexto quatro escolas públicas da esfera municipal e uma escola privada de atuação do professor 7. Salienta-se, no caso da professora 6, o comentário de que, ao mesmo tempo em que os alunos apresentaram uma boa receptividade, também demonstraram certa preocupação em ter conteúdos a mais para a avaliação escrita da disciplina.

$\mathrm{Na}$ escola privada da professora 4, ocorreu um fato interessante: os alunos do $8^{\circ}$ ano apresentaram certa resistência na utilização do material, justificada por quererem a realização constante de aulas práticas; enquanto na turma do $9^{\circ}$ ano os alunos responderam satisfatoriamente ao desenvolvimento das aulas com o material. Ou seja, foram observadas diferenças dentro da própria escola.

Já na escola pública da professora 1 , houve unanimidade nas três turmas de $9^{\circ}$ ano com as quais foi trabalhado o material, tendo os alunos apresentado grande resistência à utilização desse instrumento de ensino, também com a justificativa de solicitarem a todo instante atividades práticas. Essa resistência inicial apresentada pelas turmas da professora 1 deu-se provavelmente devido ao fato de essa professora valorizar as vivências; inclusive, quando utiliza pequenos textos, como reportagens de jornais para tratar de determinados assuntos, realiza esse procedimento em momentos curtos da aula.

Essa atitude manifestada pelos alunos na unidade de ensino da professora 1 faz parte do que Vago (2003) e Souza Júnior e Darido (2003) denominam de cultura escolar, caracterizada pela manutenção do que está posto, ocorrendo resistência dos alunos diante de qualquer tipo de mudança ou apresentação de novas propostas pedagógicas.

Assim, observa-se que os alunos em questão estão acostumados a ter de forma única nas aulas ou em grande parte delas a realização de atividades práticas, evidenciando a tradição do componente curricular direcionado exclusivamente ao aprender determinados movimentos, sem atribuir-lhes significado (BRASIL, 1997; 1998; BETTI, 2005; GONZÁLEZ; FENSTERSEIFER, 2009).

Ao estabelecer uma relação entre escolas públicas e privadas, verificou-se que não houve uma diferença relevante em relação ao impacto inicial do material didático, pois tanto se registrou uma receptividade favorável em quatro escolas públicas - professores 2, 5, 6 e 8 , na escola particular do professor 7 e em uma das turmas da instituição particular da professora 4, como também, em outra turma dessa mesma professora 4, os alunos mostraram-se resistentes, juntamente com as turmas da escola pública da professora 1 .

Quando os participantes foram questionados quanto às dificuldades apresentadas pelos alunos no trato do material didático, mencionaram a leitura dos textos. Entende-se que essa dificuldade não é característica da Educação Física, mas do atual cenário educacional, no qual 
muitos estudantes apresentam pouca concentração nas leituras e pequeno nível de interpretação de textos.

Nesse sentido, adverte-se para a necessidade de os textos a serem trabalhados com os alunos apresentarem relação com o cotidiano deles, favorecendo a concentração e o envolvimento acerca dos conteúdos tratados. Além de se atentarem, conforme salientam Galatti, Paes e Darido (2010), para a utilização de uma linguagem condizente à faixa etária envolvida.

Ao serem questionados sobre o interesse dos alunos na realização das tarefas do material, os professores destacaram que eles se mostraram motivados e interessados nas atividades de rápida execução e reduzida necessidade de parte escrita, tais como preenchimento de quadros, pequenos registros das vivências e interligação do termo à sua definição. Entretanto, quando solicitados para a elaboração de um texto envolvendo o assunto tratado, houve quase unanimidade entre os professores dos dois grupos ao relatarem o desinteresse das turmas para a realização dessa tarefa. Somente a professora 4 comentou que parte dos alunos do $9^{\circ}$ ano se mostrou motivada, devido ao fato de estar realizando atividades de produção de textos visando à preparação para provas que dão acesso a determinadas escolas de Ensino Médio.

Destaca-se que as atividades desenvolvidas no material didático utilizado no estudo tratam essencialmente de aspectos conceituais. Em Barroso (2008) e Barros e Darido (2010), os alunos apresentaram resultados positivos, quando, nos respectivos estudos, foram observadas aulas em que se contemplaram conteúdos pertencentes à dimensão conceitual do conteúdo.

Verifica-se que a preocupação em incorporar conteúdos conceituais pode ser identificada em trabalhos que apresentam a proposta de elaboração de materiais didáticos impressos (GALATTI, 2006; RODRIGUES, 2009; DARIDO, 2011; RUFINO, 2012; IMPOLCETTO, 2012), como também em material didático audiovisual (CARVALHO, 2012) e material didático digital (FRANCO, 2014).

Nesse tópico de discussão, observou-se que os alunos, mesmo não estando acostumados ao livro didático no componente curricular Educação Física, podem apresentar respostas positivas durante a utilização desse tipo de material, desde que as atividades sejam elaboradas de forma a contemplar o interesse e a curiosidade dos estudantes.

\section{Considerações finais}

A pesquisa utilizou o material didático do estado do Rio Grande do Sul - caderno do professor e caderno do aluno - com o objetivo de identificar junto a professores de Educação Física escolar as possibilidades e as dificuldades de utilização do livro didático na prática pedagógica, como também verificar o envolvimento dos alunos durante as atividades norteadas por esse tipo de material.

Em relação aos professores, identificou-se que nenhum dos envolvidos no estudo apresentava experiência na utilização do livro didático em suas respectivas práticas pedagógicas.

Quanto aos fatores negativos referentes a uma possível utilização do livro didático nas aulas, destacou-se a preocupação de certo "engessamento" do ensino, quando há obrigação de seguir plenamente o que é sugerido no material, não se permitindo, portanto, flexibilidade para mudanças, inserções de atividades, retirada de tarefas, entre outros aspectos, o que torna o profissional um refém das propostas direcionadas no material.

Entretanto, ao terem a possibilidade de realizar interferências no livro didático, os professores mencionaram diversos aspectos favoráveis, como: maior organização dos conteúdos; melhor direcionamento do trabalho pedagógico; aumento da qualidade das aulas; acesso a uma diversidade de informações; contribuição aos professores que já apresentam domínio do tema, como também oferecimento de subsídios aos que têm pouco conhecimento do assunto tratado, e reflexão acerca da prática pedagógica. 
A partir desses posicionamentos, observou-se que os participantes da pesquisa se mostraram a favor da utilização de livros didáticos como instrumento de ensino para auxiliar a prática pedagógica. Contudo, alerta-se que, para a sua incorporação, há a necessidade de políticas públicas, oferecendo cursos aos professores para que possam se apropriar de maneira satisfatória desse tipo de material, bem como destinar um tempo maior para se adaptarem a essa forma de trabalhar, além de ser fundamental um olhar cuidadoso nos cursos de formação em licenciatura em Educação Física sobre esse instrumento de ensino.

Quanto aos alunos, foi possível verificar certa resistência inicial em algumas turmas para a utilização do livro didático. Isso pode ser entendido pelo fato de esse componente curricular não apresentar a tradição no trato desse tipo de material; entretanto, esse aspecto foi atenuado ao longo das aulas, com os alunos demonstrando melhor receptividade a partir do desenvolvimento das atividades. Identificou-se, na maioria dos alunos, pequeno interesse pela leitura dos textos, algo que não pode ser considerado exclusividade da Educação Física, pois essa característica também é manifestada nos demais componentes curriculares. Também em relação à produção de textos, apresentaram pouca motivação e interesse, sendo essa atividade executada por um número reduzido de alunos.

Porém, durante a realização de tarefas mais curtas no próprio livro didático, como preenchimento de quadros, pequenos registros de vivências e interligação de termos aos conceitos, os alunos demonstraram aceitação e bom envolvimento nesses tipos de atividades.

Assim, entende-se que a utilização do livro didático no componente curricular Educação Física tem muito mais a oferecer em benefícios para o desenvolvimento das aulas do que as possíveis dificuldades que possam se apresentar. Contudo, talvez o professor que já atue no ambiente escolar precise de um tempo para se adaptar à utilização desse instrumento pedagógico, justificado pelo fato de não ter sido preparado na sua formação inicial e também por esse material não fazer parte do cotidiano de suas aulas. Mas isso não significa dizer que esses fatores impossibilitem a adoção do livro didático em suas práticas pedagógicas.

É importante, porém, estar ciente de que as perguntas acerca da interação entre o professor e o livro didático - tempo de adequação para utilização, devida apropriação da ferramenta pedagógica, habituar-se à realização de alterações no documento para atender às realidades educacionais, atenção destinada ao assunto nos cursos de formação inicial e continuada - somente terão respostas contundentes ao longo do tempo e se efetivamente houver incorporação desse instrumento de ensino ao trabalho pedagógico do professor de Educação Física escolar.

\title{
THE TEXTBOOK IN SCHOOL PHYSICAL EDUCATION: VIEW OF TEACHERS AND STUDENTS
}

\begin{abstract}
The aim of the study was to identify possibilities and difficulties that Physical Education (PE) teachers have to use the textbook in their academic practice and verify the involvement of students in activities that use this kind of material. The action research method was used, with the participation of teachers of the last years of middle school. The teachers were favorable to the use of the textbook, provided they have freedom to make changes in the material. As for the students, there was a better acceptance in short tasks. Thus, it is understood that the use of the textbook in PE can offer benefits in the development of classes.
\end{abstract}

Keywords: School. Physical Education. Academic Material. 


\section{EL LIBRO DIDÁCTICO EN LA EDUCACIÓN FÍSICA ESCOLAR: VISIÓN DE PROFESORES Y ALUMNOS}

\section{Resumen}

El objetivo de este estudio fue identificar junto con los profesores de Educación Física (EF) escolar posibilidades y dificultades relacionadas al uso del libro didáctico en la práctica pedagógica y, verificar la participación de los alumnos durante las actividades propuestas por ese tipo de material. Se utilizó el método de investigación-acción, contando con la participación de los profesores de los años finales de la Enseñanza Fundamental. Los profesores se mostraron favorables al uso del libro didáctico, siempre que tengan libertad de hacer modificaciones en el material. En relación a los alumnos, se puede decir que, aceptaron mejor las tareas cortas. Concluimos que la utilización del libro didáctico en la EF escolar puede ofrecer beneficios para el desarrollo de las clases.

Palabras-Claves: Colegio. Educación Física. Material Didáctico.

\section{Referências}

APPLE, M. W. Cultura e comércio do livro didático. In: Trabalho docente e textos: economia política das relações de classe e de gênero em educação. Porto Alegre: Artes Médicas, 1995. p. 81-105.

ARROYO, M. G. Experiências de inovação educativa: o currículo na prática da escola. In: MOREIRA, A. F. B. Currículo: políticas e práticas. 4. ed. Campinas: Papirus, 2001. p. 131164.

BARDIN, L. Análise de conteúdo. Lisboa: LDA, 1991.

BARROS, A. M. de. Os conteúdos e a prática pedagógica dos professores de Educação Física: análise do currículo do estado de São Paulo. 2014. 193 f. Tese (Doutorado em Desenvolvimento Humano e Tecnologias) - Instituto de Biociências, Universidade Estadual Paulista, Rio Claro, 2014.

; DARIDO, S. C. Práticas pedagógicas de dois professores mestres em Educação Física escolar e o tratamento da dimensão conceitual dos conteúdos. Revista Brasileira de Educação Física e Esporte, São Paulo, v. 23, n. 1, p. 61-75, jan./mar. 2010.

BARROSO, A. L. R. Voleibol escolar: uma proposta de ensino nas três dimensões dos conteúdos. 2008. 226f. Dissertação (Mestrado em Ciências da Motricidade) - Instituto de Biociências, Universidade Estadual Paulista, Rio Claro, 2008.

; DARIDO, S. C. Voleibol escolar: uma proposta de ensino nas dimensões conceitual, procedimental e atitudinal do conteúdo. Revista Brasileira de Educação Física e Esporte, São Paulo, v. 24, n.2, p.179-94, abr./jun. 2010.

BETTI, M. Educação Física escolar: do idealismo à pesquisa-ação. 2002. 336f. Tese (LivreDocência em Métodos e Técnicas de Pesquisa em Educação Física e Motricidade Humana) Faculdade de Ciências, Universidade Estadual Paulista, Bauru, 2003. 
Sobre teoria e prática: manifesto pela redescoberta da Educação Física. Lecturas, Educación Física y Deportes, Buenos Aires, n. 91, dez. 2005.

BETTI, M.; ZULIANI, L. R. Educação física escolar: uma proposta de diretrizes pedagógicas. Revista Mackenzie de Educação Física e Esporte, v. 1, n. 1, 2009.

BITTENCOURT, C. Livros didáticos de história: práticas e formação docente. In: DALBEN, A.; DINIZ, L.; LEAL, L; SANTOS, L. (Org.). Coleção didática e prática de ensino. Belo Horizonte: Autêntica, 2010. p. 544-563.

BRACHT, V. A prática pedagógica em Educação Física: a mudança a partir da pesquisa-ação. Revista Brasileira de Ciência do Esporte, Campinas, v. 23, n. 2. p. 9-29, jan. 2002.

BRASIL. Ministério da Educação. Base Nacional Comum Curricular. Brasília: MEC, 2017. - Secretaria de Ensino Fundamental. Parâmetros curriculares nacionais: Educação Física, $1^{\circ}$ e $2^{\circ}$ ciclos. Brasília: MEC / SEF, 1997.

Secretaria de Ensino Fundamental. Parâmetros curriculares nacionais: Educação Física, $3^{\circ}$ e $4^{\circ}$ ciclos. Brasília: MEC / SEF, 1998.

BUSTAMANTE, G. O. Educação Física escolar e a educação para o lazer. 2003. 130 f. Dissertação (Mestrado em Ciências da Motricidade) - Instituto de Biociências, Universidade Estadual Paulista, Rio Claro, 2003.

CAPARROZ, F. E. Entre a educação física na escola e a educação física da escola: a educação física como componente curricular. Campinas: Autores Associados, 2005.

CARVALHO, A. O. Ginástica na escola e a utilização da tecnologia audiovisual (vídeo). 2012. 147 f. Dissertação (Mestrado em Desenvolvimento Humano e Tecnologias) - Instituto de Biociências, Universidade Estadual Paulista, Rio Claro, 2012.

DARIDO, S. C. (Org.). Educação Física escolar: compartilhando experiências. São Paulo: Phorte, 2011.

et al. Livro didático na Educação Física escolar: considerações iniciais. Motriz, Rio Claro, v.16, n.2, p. 450-457, abr./jun. 2010.

; RANGEL, I. C. A. (Coord.). Educação Física na escola. Rio de Janeiro: Guanabara Koogan, 2005.

ELLIOTT, J. El cambio educativo desde la investigación-acción. 4. ed. Madri: Ediciones Morata, S. L., 2005.

FAGANELLO, F. R. Análise dos livros de atletismo como subsídio para o seu ensino no campo escolar. 2008. 158 f. Dissertação (Mestrado em Ciências da Motricidade) - Instituto de Biociências, Universidade Estadual Paulista, Rio Claro, 2008.

FRANCO, L. C. P. Jogos digitais educacionais nas aulas de Educação Física: Olympia, um videogame sobre os jogos olímpicos. 2014. 168 f. Tese (Doutorado em Desenvolvimento 
Humano e Tecnologias) - Instituto de Biociências, Universidade Estadual Paulista, Rio Claro, 2014.

GALATTI, L. R. Pedagogia do esporte: o livro didático como mediador no processo de ensino e aprendizagem dos jogos esportivos coletivos. 2006. 139f. Dissertação (Mestrado em Educação Física) - Faculdade de Educação Física, Universidade Estadual de Campinas, Campinas, 2006.

; PAES, R. R.; DARIDO, S. C. Pedagogia do Esporte: livro didático aplicado aos Jogos Esportivos Coletivos. Motriz, Rio Claro, v. 16, n. 3, p. 751-761, jul./set. 2010.

GONZÁLEZ, F. J. Projeto curricular e educação física: o esporte como conteúdo escolar. In: REZER, R. (Org.). O fenômeno esportivo: ensaios crítico-reflexivos. Chapecó: Argos, 2006. p. 69-109.

Sistema de classificação de esportes com base nos critérios: cooperação, interação com o adversário, ambiente, desempenho comparado e objetivos táticos da ação. Lecturas, Educación Física y Deportes, Buenos Aires, v. 71, abr. 2004.

; FENSTERSEIFER, P. E. Entre o "não mais" e o "ainda não": pensando saídas do não lugar da Educação Física escolar I. Cadernos de Formação Revista Brasileira de Ciências do Esporte, p. 9-24, set./2009.

IMPOLCETTO, F. M. Jogos e ética na perspectiva da Educação Física escolar. 2005. 212 f. Dissertação (Mestrado em Ciências da Motricidade) - Instituto de Biociências, Universidade Estadual Paulista, Rio Claro, 2005.

Livro didático como tecnologia educacional: uma proposta de construção coletiva para a organização curricular do conteúdo voleibol. 2012. 320 f. Tese (Doutorado em Desenvolvimento Humano e Tecnologias) - Instituto de Biociências, Universidade Estadual Paulista, Rio Claro, 2012.

LADEIRA, M. F. T. et al. O impacto da nova proposta do estado de São Paulo na opinião dos professores de Educação Física. In: SEMINÁRIO DE METODOLOGIA DE ENSINO DOS PROFESSORES DE EDUCAÇÃO FÍSICA, 2., 2008, São Paulo. Anais... São Paulo: USP, 2008.

LIÇÕES DO RIO GRANDE. Caderno do aluno. $7^{\mathrm{a}}$ e $8^{\mathrm{a}}$ séries Ensino Fundamental. 2009a. Disponível em: 〈http://www.educacao.rs.gov.br/dados/refer_curric_aluno_EF_78.pdf $>$ Acesso em: 10 jun. 2016.

Linguagens, códigos e suas tecnologias. Artes e Educação Física. Caderno do professor. Ensino Fundamental e Médio. 2009b. Disponível em:

<http://www.educacao.rs.gov.br/dados/refer_curric_prof_vol2.pdf > Acesso em: 10 jun. 2016.

MUNAKATA, K. Investigações acerca dos livros escolares no Brasil: das ideias à materialidade. In: CONGRESSO IBEROAMERICANO DE HISTÓRIA DE LA EDUCACIÓN LATINOAMERICANA, 6., San Luis Potosi. Anais... San Luis Potosi, 2003. 
PARANÁ. Secretaria de Estado da Educação do Paraná. Diretrizes curriculares da educação básica: Educação Física. Paraná, 2008.

POLIDORO, L. de F.; STIGAR, R. A transposição didática: passagem do saber científico para o saber escolar. Revista de Teologia \& Cultura, n. 27, p. 153-159. 2010.

RIO GRANDE DO SUL. Secretaria de Estado da Educação. Referencial curricular: lições do Rio Grande. Linguagens, códigos e suas tecnologias. Artes e Educação Física. v. 2. Porto Alegre, 2009.

RODRIGUES, H. A. Basquetebol na escola: construção, avaliação e aplicabilidade de um livro didático. 2009. 92 f. Dissertação (Mestrado em Ciências da Motricidade) - Instituto de Biociências, Universidade Estadual Paulista, Rio Claro, 2009.

; DARIDO, S. C. O livro didático na Educação Física escolar: a visão dos professores. Motriz, Rio Claro, v. 17, n. 1, p. 48-62, jan./mar. 2011.

RUFINO, L. G. B. “Campo de luta": o processo de construção coletiva de um livro didático na Educação Física no Ensino Médio. 2012. 366 f. Dissertação (Mestrado em Desenvolvimento Humano e Tecnologias) - Instituto de Biociências, Universidade Estadual Paulista, Rio Claro, 2012.

SACRISTÁN, J. G. O currículo apresentado aos professores. In: Currículo: uma reflexão sobre a prática. Porto Alegre: Artmed, 2000. p. 147-163.

SÃO PAULO. Secretaria da Educação do Estado de São Paulo. Proposta curricular Educação Física: ensino fundamental ciclo II e ensino médio. São Paulo, 2008.

SOUZA JÚNIOR, O. M.; DARIDO, S. C. Influências da cultura escolar no desenvolvimento de propostas coeducativas em aulas de Educação Física. Motriz, Rio Claro, v. 9, n. 3, p. 143151, set./dez. 2003.

; GALVÃO, A. M. de O. História das disciplinas escolares e história da educação: algumas reflexões. Educação e Pesquisa, São Paulo, v. 31, n. 3, p. 391-408, set./dez. 2005.

THIOLLENT, M. Metodologia da pesquisa-ação. 12. ed. São Paulo: Cortez, 2003.

VAGO, T. M. A Educação Física na cultura escolar: discutindo caminhos para a intervenção e a pesquisa. In: BRACHT, V.; CRISORIO, R. (Org.). A Educação Física no Brasil e na Argentina: identidades, desafios e perspectivas. Campinas: Autores Associados, 2003. p. 197-221.

ZABALA, A. A prática educativa: como ensinar. Porto Alegre: Artmed, 1998.

Recebido em: 07/07/2016

Revisado em: 17/05/2017

Aprovado em: 22/06/2017

Endereço para correspondência:

al.barroso@uol.com.br 
André Luís Ruggiero Barroso

Universidade Estadual Paulista

Avenida 24 A, 1515

13506-900 Rio Claro - SP 